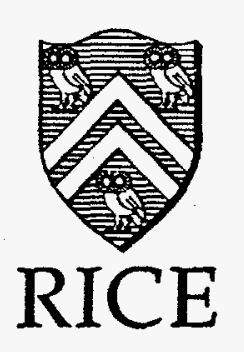

\title{
COAL COMBUSTION: EFFECT OF PROCESS CONDITIONS ON CHAR REACTIVITY
}

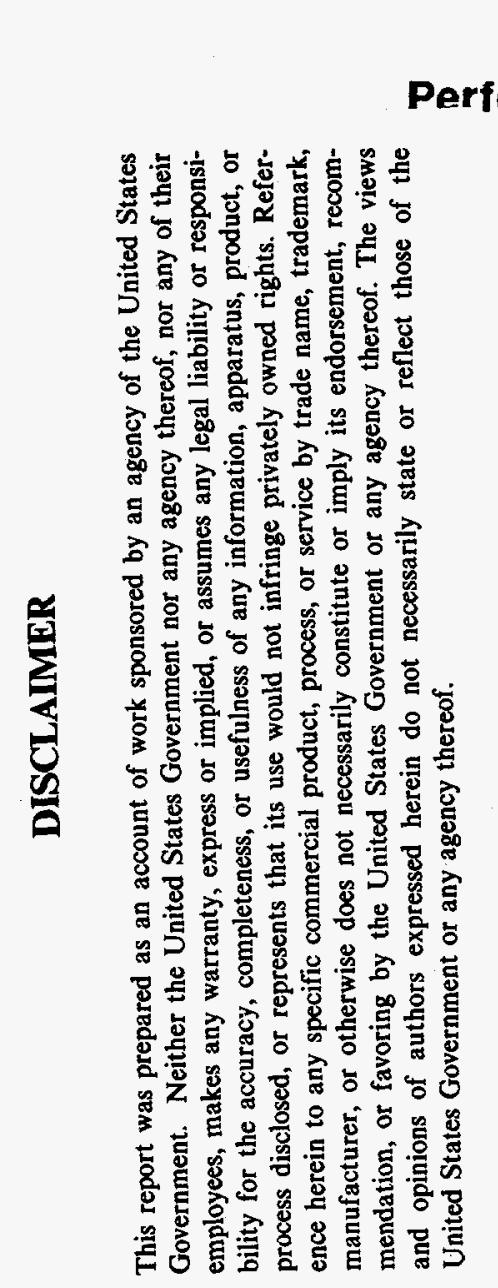

\author{
Quarterly Technical Report
}

Performance Period: 1/1/95 -3/31/95 (Quarter \#14)

\author{
Submitted to the \\ Department of Energy
}

Grant Number DE-FG22-91PC91307

Grant Period: $9 / 1 / 1991$ to $6 / 1 / 1995$

PRINCIPAL INVESTIGATOR

Kyriacos Zygourakis

Department of Chemical Engineering

Rice University

Houston, Texas 77251-1892

DOE Technical Project Officer

Kamalendu Das

Morgantown Energy Technology Center

"U.S. DOE Patent Clearance is not required prior to the publication of this document"

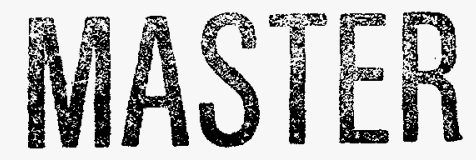




\section{DISCLAIMER}

Portions of this document may be illegible in electronic image products. Images are produced from the best available original document. 


\section{PROJECT OBJECTIVES}

The project will quantify the effect of the following pyrolysis conditions on the macropore structure and on the subsequent reactivity of chars: (a) pyrolysis heating rate; (b) final heat treatment temperature (HTT); (c) duration of heat treatment at HTT (or soak time); (d) pyrolysis atmosphere $\left(\mathrm{N}_{2}\right.$ or $\mathrm{O}_{2} / \mathrm{N}_{2}$ mixtures); (e) coal particle size (100-1,000 $\mu \mathrm{m}$ in diameter); (f) sulfur-capturing additives (limestone); and ( $\mathrm{g}$ ) coal rank. Pyrolysis experiments will be carried out for three coals from the Argonne collection: (1) a high-volatile bituminous coal with high ash content (Illinois \#6), (2) a bituminous coal with low ash content (Utah Blind Canyon) and (3) a lower rank subbituminous coal (Wyodak-Anderson seam).

Task A: We will obtain the time histories and follow the fate of single particles during pyrolysis in our TGA/VMI reactor. The experiments will be videotaped and digital images at several time instants will be acquired and analyzed on the image processor. For each run, we will measure particle swelling and shape, as well as the number and size of volatile bubbles evolving from each particle. For selected sets of conditions, several char samples will be collected and polished sections will be prepared so that we can accurately analyze the internal structure of the char particles. We will pay particular attention to the existence of correlations between particle swelling and macropore surface area as well as to the fate of ash inclusions during pyrolysis.

Task B: A different set of pyrolysis experiments will be immediately followed by combustion experiments. Without removing the particles from the TGA/VMI reactor, the char samples will be reacted with $\mathrm{O}_{2}$ to complete conversion at high temperatures. Different gas flow rates of gases and $\mathrm{O}_{2}$ concentrations will be used to investigate the effect of external mass transfer limitations. Issues to be addressed in this study will include the influence of particle swelling and ash content on thermal ignitions.

Task C: We will use mathematical models to simulate combustion of char particles in the regime of strong diffusional limitations. Digitized particle cross-sections obtained from our studies will be used as computational grids for these simulations and the average behavior will be obtained by analyzing a large number of particle cross-sections. The observed reactivity vs. conversion patterns will be analyzed and classified. These patterns will then be used in transient models to describe ignition and extinction phenomena in char combustion. 


\section{SUMMARY}

A systematic study was carried out in the past quarter to validate the mathematical model for ignition phenomema presented in the previous quarterly report. Model predictions of the effect of pyrolysis heating rate, particle size, and oxygen concentration on ignition behavior are in excellent agreement with experimental results. Moreover, our results show that the model can be used to estimate the particle temperature during ignition and the minimum ignition temperature for various process conditions.

\section{EXPERIMENTAL PROCEDURES}

The TGA/VMI reactor described in earlier reports was used to perform sequential pyrolysis and combustion experiments. All experiments were repeated at least once to check for reproducibility. We studied three size fractions of Illinois \#6 coal from the Argonne premium coal sample collection: $20-25$ mesh $(710-840 \mu \mathrm{m})$, 28-32 mesh (500-600 $\mu \mathrm{m})$ and 50-60 mesh $(250-300 \mu \mathrm{m})$. Table 1 gives the experimental conditions for the pyrolysis and combustion runs.

Table 1

Experimental Conditions for Pyrolysis and Combustion

Pyrolysis Stage:

Rate : $0.1,1.0$ and $10.0{ }^{\circ} \mathrm{C} / \mathrm{s}$

Heat Treatment Temperature(HTT): $7000^{\circ} \mathrm{C}$

Soak Time: $3 \mathrm{~min}$.

Flowing gas: $100 \%$ Nitrogen

Combustion Stage:

Reaction Temperature: 550 and $625^{\circ} \mathrm{C}$

Flowing gas: 21 and $33 \%$ Oxygen

Gas flow rate: $360 \mathrm{sccm}$. 
The combustion temperatures of Table 1 were chosen so that the chars would react in the regime of significant intraparticle diffusional limitations.

\section{COMPARISON WITH EXPERIMENTAL RESULTS}

To determine whether our mathematical model is able to predict the ignition behavior we observed experimentally, we computed the multiplicity regions for all the process conditions used for our experimental runs. The values of the particle radius, porosity and macropore surface area used in this study are listed in Table 2 for the 50-60 mesh size fraction and Table 3 for the 28-32 mesh size fraction respectively. These structural parameters were measured with the methods described in detail elsewhere $[1,2]$.

Table 2

Effect of pyrolysis heating rate on char structure.

Coal particle size: 50-60 mesh [1].

\begin{tabular}{|c|c|c|c|}
\hline $\begin{array}{c}\text { heating rate, } \\
\mathrm{C} / \mathrm{s}\end{array}$ & $\begin{array}{c}\text { average particle } \\
\text { radius, } \mu \mathrm{m}\end{array}$ & macroporosity & $\begin{array}{c}\text { macropore } \\
\text { surface area, } \\
\mathrm{cm}^{2} / \mathrm{cm}^{3}\end{array}$ \\
\hline 0.1 & 168.5 & 0.33 & 659 \\
\hline 1.0 & 168.5 & 0.55 & 1479 \\
\hline 10.0 & 195.6 & 0.72 & 2951 \\
\hline
\end{tabular}

Table 3

Effect of pyrolysis heating rate on char structure.

Coal particle size: 28-32 mesh [2].

\begin{tabular}{|c|c|c|c|}
\hline $\begin{array}{c}\text { heating rate, } \\
\mathrm{C} / \mathrm{s}\end{array}$ & $\begin{array}{c}\text { average particle } \\
\text { radius, } \mu \mathrm{m}\end{array}$ & macroporosity & $\begin{array}{c}\text { macropore } \\
\text { surface area, } \\
\mathrm{cm}^{2} / \mathrm{cm}^{3}\end{array}$ \\
\hline 0.1 & 317.0 & 0.59 & 853 \\
\hline 1.0 & 325.0 & 0.60 & 1260 \\
\hline 10.0 & 407.0 & 0.65 & 1046 \\
\hline
\end{tabular}


Since the data in Tables 2 and 3 were obtained from direct measurement in our lab, the results from the model can be used to explain the experimental observations of the effect of process conditions on char particle ignition. For the subsequent discussion, only stagnant flow is considered and the micropore radius is taken to be $5 \AA$.

\subsection{Effect of pyrolysis heating rate}

Our experimental results showed that the pyrolysis heating rate significantly affects the radius of the char particles as well as their macroporosity and macropore surface area. These results are tabulated in Tables 2 and 3 above. Consequently, the pyrolysis heating rate has a profound effect on the likelihood of particle ignitions.

The model predictions showing this effect are presented in Figure 1 for the 5060 mesh particles. In this case, the model predicts that the ignition is only possible for char particles produced at the highest heating rate of $10{ }^{\circ} \mathrm{C} / \mathrm{s}$, when the char is gasified at $550{ }^{\circ} \mathrm{C}$ with $33 \%$ oxygen. Note also that no multiple solution region exist for particles produced at the other two pyrolysis heating rates. These results are in excellent agreement with the experimental results presented in Figure 2 where we plot the reaction rate defined as follows:

$$
R_{s}(t)=\frac{1}{1-x} \frac{d x}{d t}=-\frac{1}{m(t)} \frac{d m(t)}{d t}
$$

where $x$ is the conversion of the solid and $m(t)$ is the mass of char remaining unreacted at time $t$. The plots in Figure 2 show that the char ignites only when the highest pyrolysis heating rate, $10^{\circ} \mathrm{C} / \mathrm{s}$, is used. This is depicted on the curve as a "spike" or sharp increase of the reaction rate for a very short time. The ignition is also observed and recorded in our video sequences as a luminous flame engulfing the char particle. As shown in Table 3, high heating rates produce chars with large macroporosities and macropore surface areas. Our parametric study shows that the minimum ignition temperature decreases with increasing macroporosity and macropore surface area due to enhancements in the combustion rates.

The simulation results for 28-32 mesh particles are shown in Figure 3. When combustion is carried out at $5500^{\circ} \mathrm{C}$ with $33 \%$ oxygen, model predictions show that 
ignitions are possible for char particles produced at pyrolysis heating rates of 10 and 1 ${ }^{\circ} \mathrm{C} / \mathrm{s}$. These model predictions agree with our experimental results reported on Figure 4.

\subsection{Effect of particle size}

Video tapes from combustion experiments show that larger char particles tend to be more reactive and to ignite more easily. Figures 5 and 6 present the model predictions on the effect of particle size for two pyrolysis heating rates $\left(10\right.$ and $1{ }^{\circ} \mathrm{C} / \mathrm{s}$ respectively).

For the higher heating rate of $10{ }^{\circ} \mathrm{C} / \mathrm{s}$ (Figure 5), the model predicts that both size fractions will ignite at a combustion temperature of $550{ }^{\circ} \mathrm{C}$ with $33 \%$ oxygen. The larger particles will achieve a slightly higher solid temperature. On the other hand, Figure 6 indicates that only the larger particles (28-32 mesh fraction) may ignite, when the lower heating rate of $1{ }^{\circ} \mathrm{C} / \mathrm{s}$ is used to prepare the chars. These results confirm our experimental observations of the effect of particle size presented in Figures 7 and 8.

\subsection{Effect of oxygen concentration}

Some model predictions of the effect of ambient oxygen concentration on particle ignitions are presented in Figures 9 and 10 for the two mesh fractions chars (50-60 and 28-32 mesh, respectively) produced using $10{ }^{\circ} \mathrm{C} / \mathrm{s}$.

In both cases, the model predicts that the minimum ignition temperature decreases with increasing oxygen concentration. There is only one solution (unignited state) when combustion takes place at $550{ }^{\circ} \mathrm{C}$ with $21 \%$ oxygen concentration. Therefore, we do not expect to observe particle ignitions when these three chars are reacted at these conditions. However, the model predicts three steady-states when these three chars are burned at $550^{\circ} \mathrm{C}$ with $33 \%$ ambient oxygen concentration. All these predictions are in excellent agreement with our experimental observations presented in Figures 11 and 12.

Another interesting comparison between model and experiment that should be pointed out here involves the results for the char produced from 28-32 mesh coal particles at $10{ }^{\circ} \mathrm{C} / \mathrm{s}$ pyrolysis heating rate and combusted at $625^{\circ} \mathrm{C}$ with $21 \%$ oxygen 
concentration. Although the experimental reactivity pattern (Figure 12) shows some sharp changes in the reaction rate (possibly indicating ignition), no flames were visible on the video sequences for these experiments and only sudden and rapid consumption of the particles was observed. One possible explanation for this behavior can be based on the model predictions shown in Figure 23. These predictions show an ignited steady-state solution for $21 \%$ oxygen concentration that is a few hundred degrees lower than the ignited particle temperature predicted for $33 \%$ oxygen concentration.

\section{CONCLUSIONS}

Model predictions of the effect of pyrolysis heating rate, particle size, and oxygen concentration on ignition behavior are in excellent agreement with experimental results. Moreover, the model estimates the particle temperature during ignition and the minimum ignition temperature for various process conditions. As shown in the previous report, the minimum ignition temperature decreases with increasing heating rate, particle size, and oxygen concentration.

The model predictions explain the perhaps counter-intuitive experimental results showing that large coal particles react faster than smaller particles in the regime of diffusional limitations. This is because the larger particles ignite more easily and ignitions bring the particle temperature to much higher values.

\section{REFERENCES}

1. Zygourakis, K. "Effect of Pyrolysis Conditions on the Macropore Structure of Coal-Derived Chars." Energy and Fuels. 7(1): 33-41, 1993.

2. Boissière, F. Influence of Pyrolysis Conditions on Macropore Structure of Char Particles. 1993. 


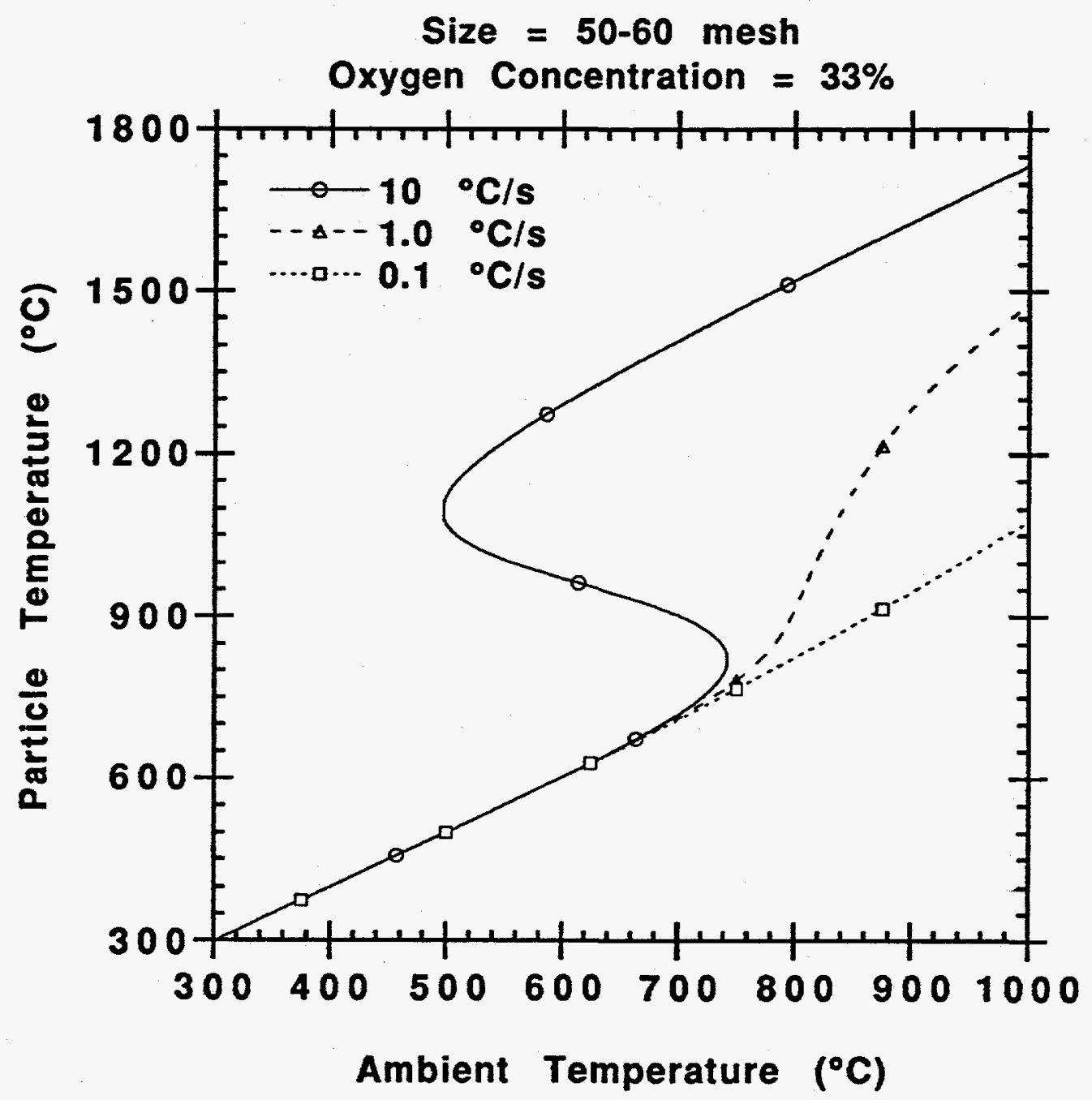

Figure 1: Effect of pyrolysis heating rate on ignition for 50-60 mesh fraction chars. 


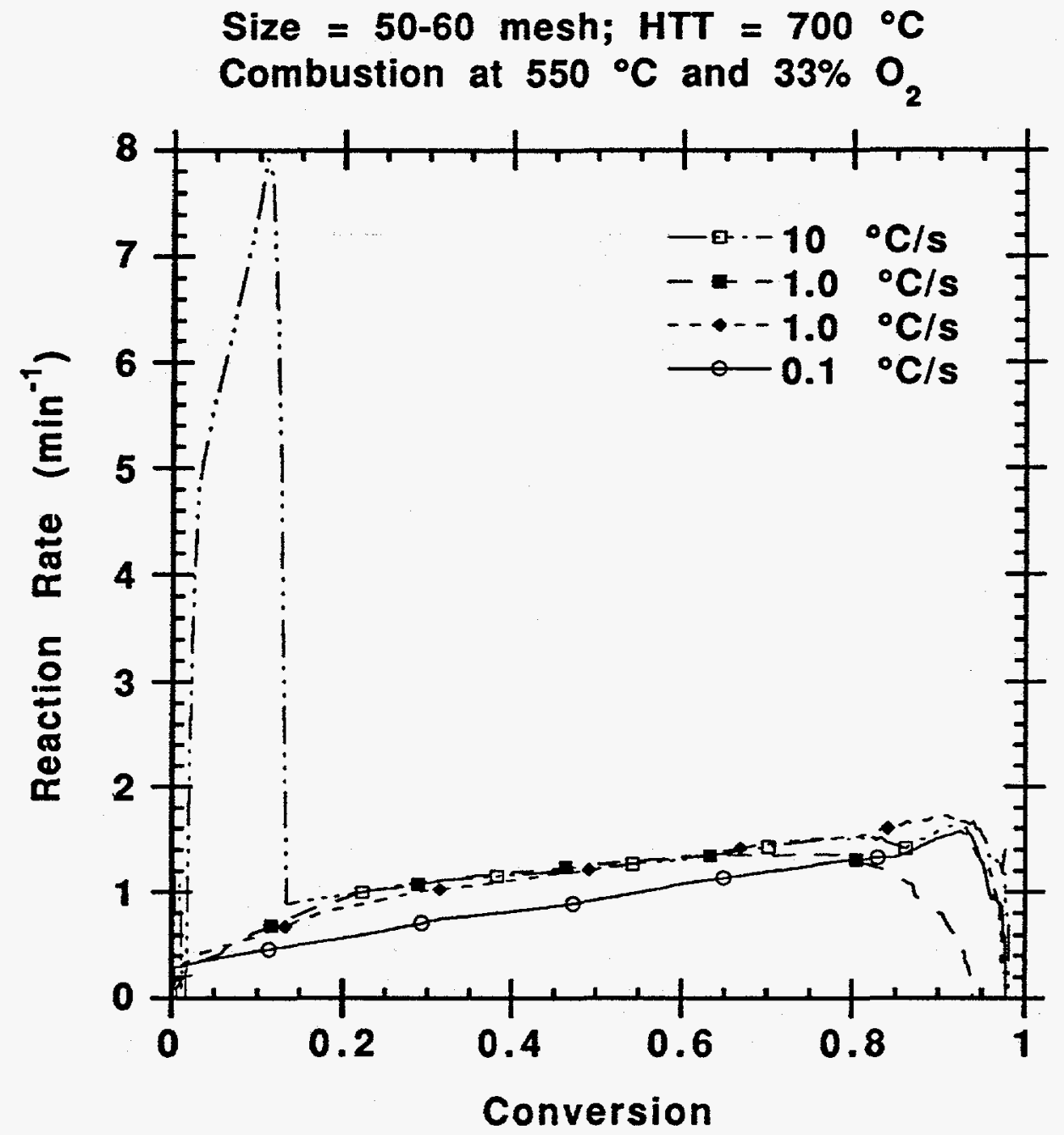

Figure 2: Reactivity patterns for 50-60 mesh fraction chars produced using various pyrolysis heating rates. 


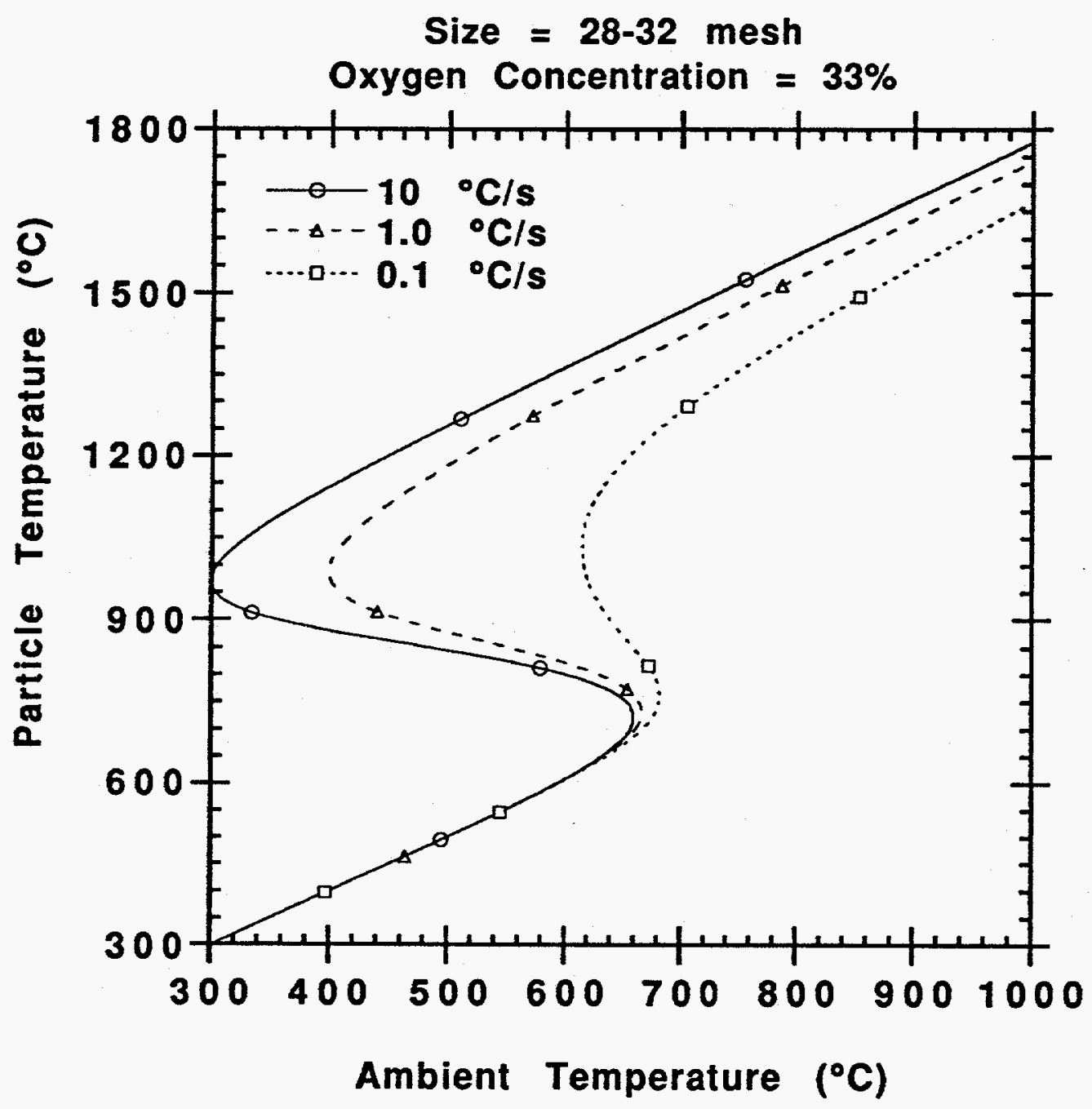

Figure 3: Effect of pyrolysis heating rate on ignition for 28-32 mesh fraction chars. 


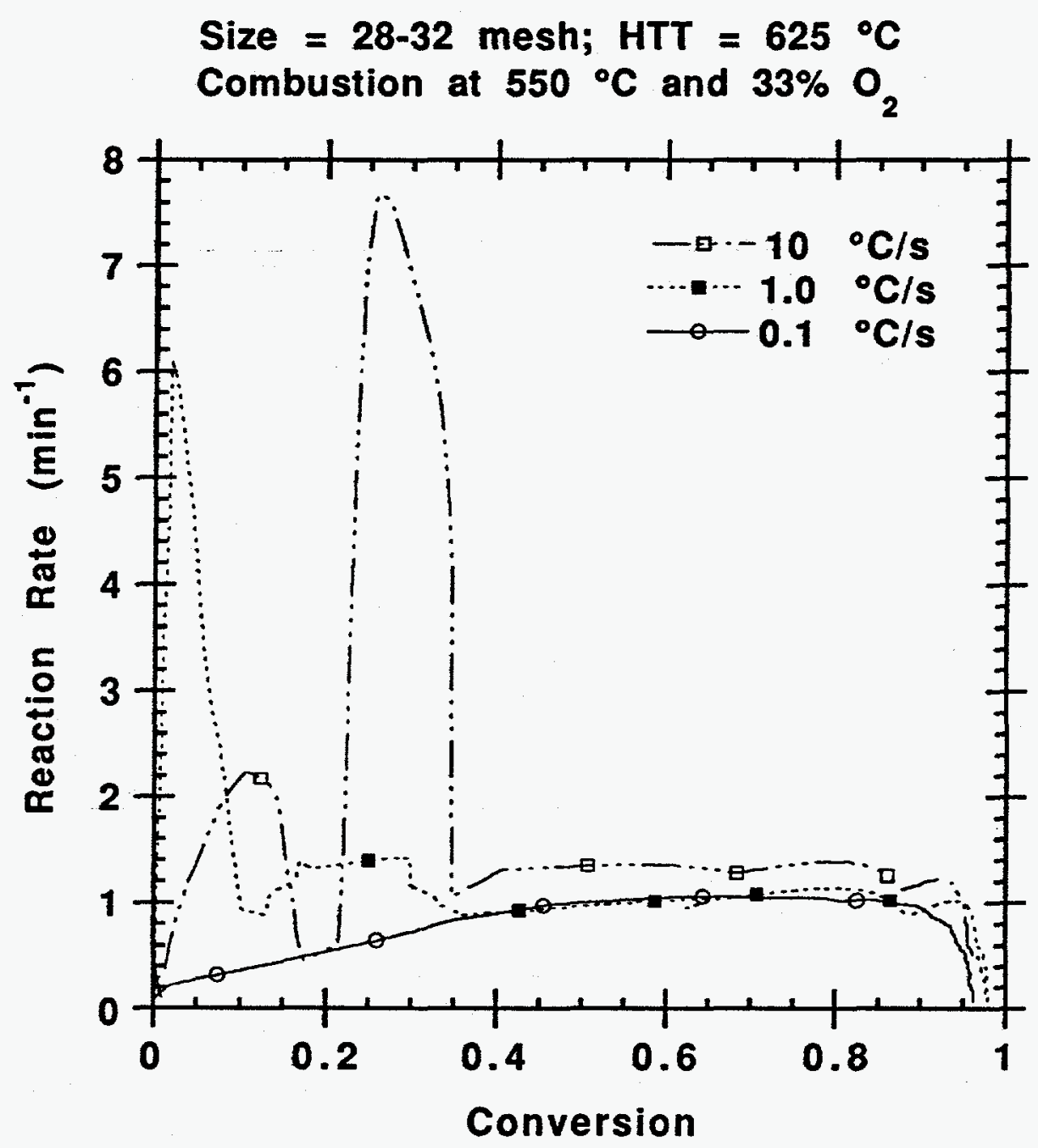

Figure 4: Reactivity patterns for 28-32 mesh fraction chars produced using various pyrolysis heating rates. 


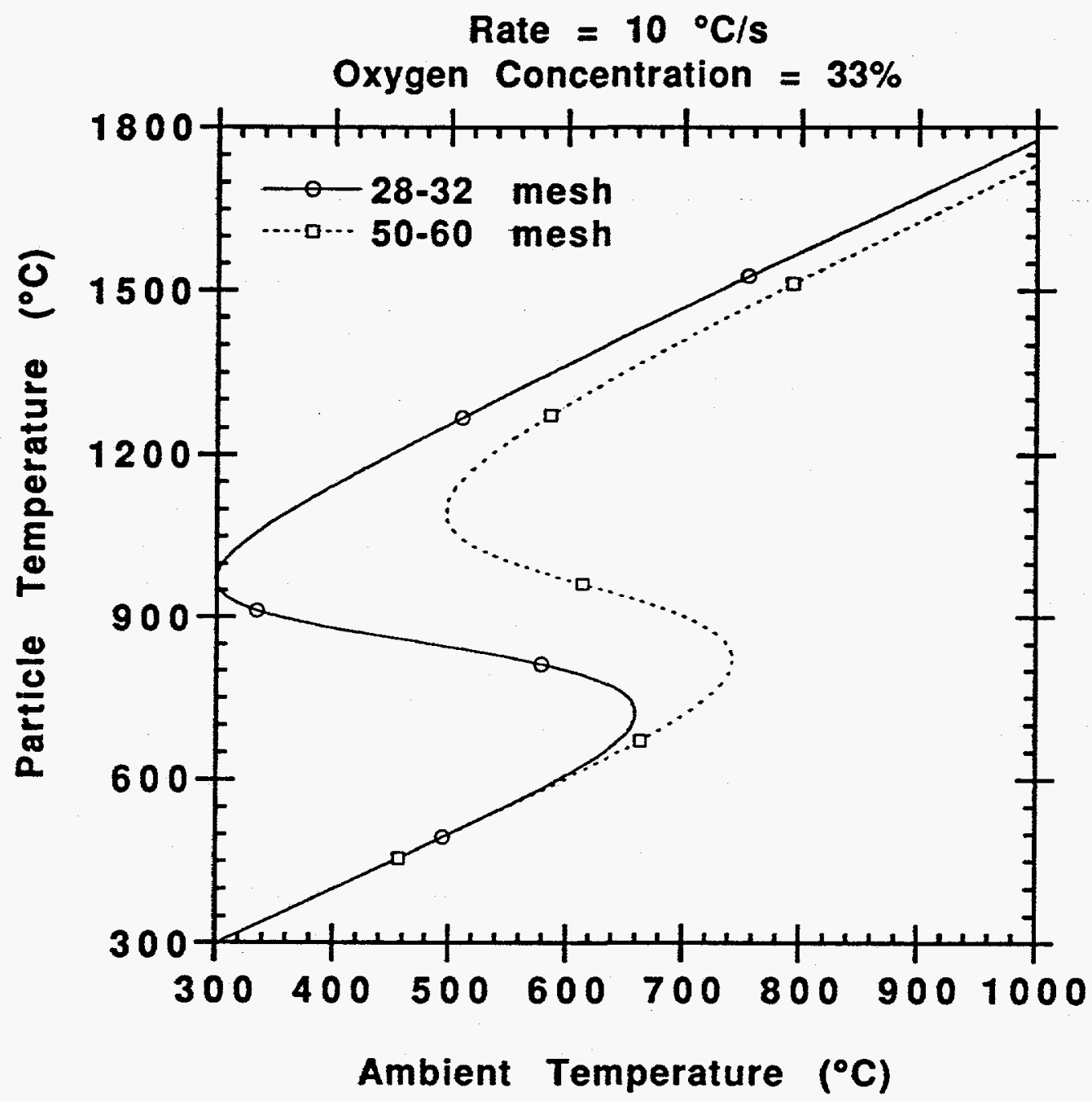

Figure 5: $\quad$ Effect of particle size on ignition for chars produced using $10 \mathrm{C} / \mathrm{s}$. 


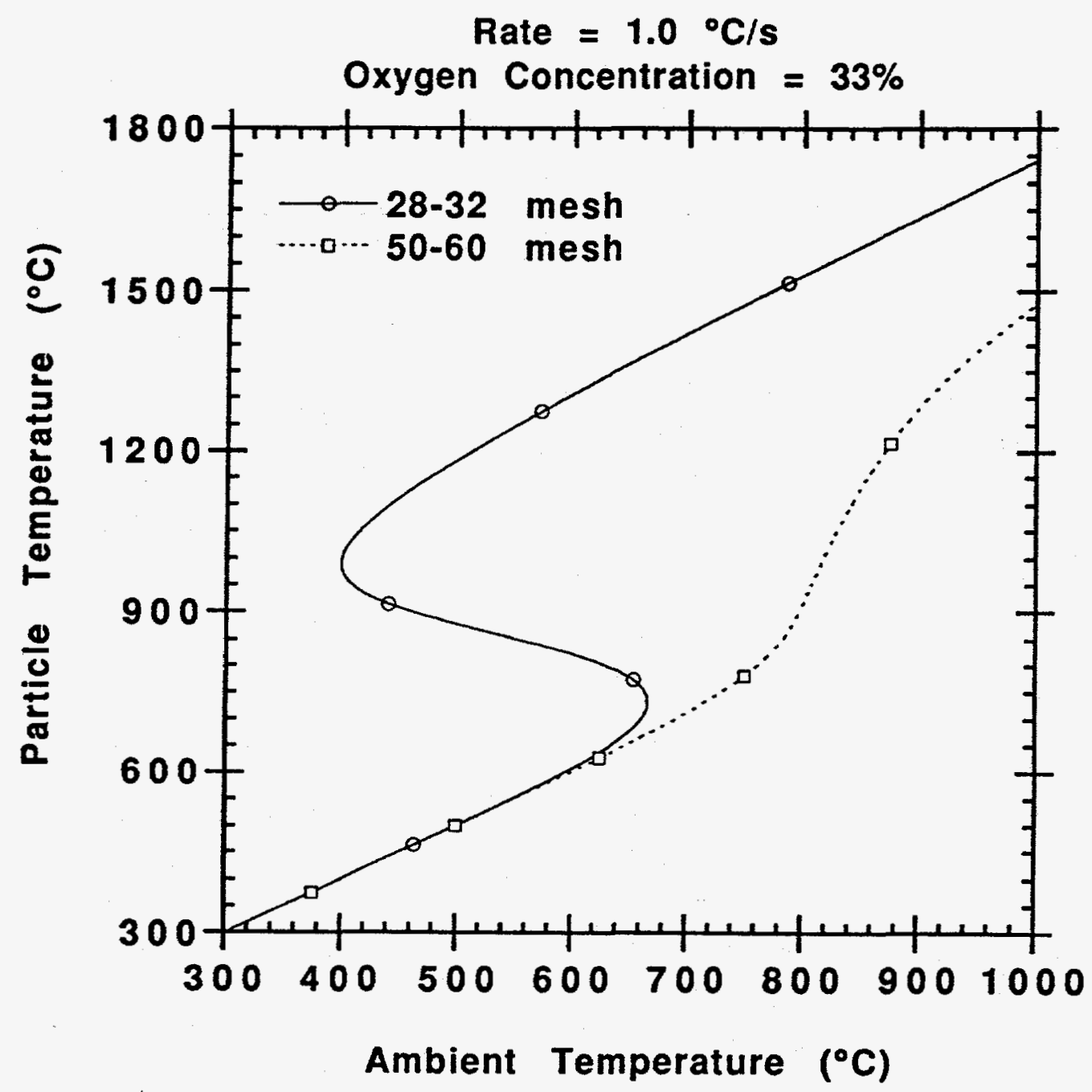

Figure 6: Effect of particle size on ignition for chars produced using $1.0^{\circ} \mathrm{C} / \mathrm{s}$. 


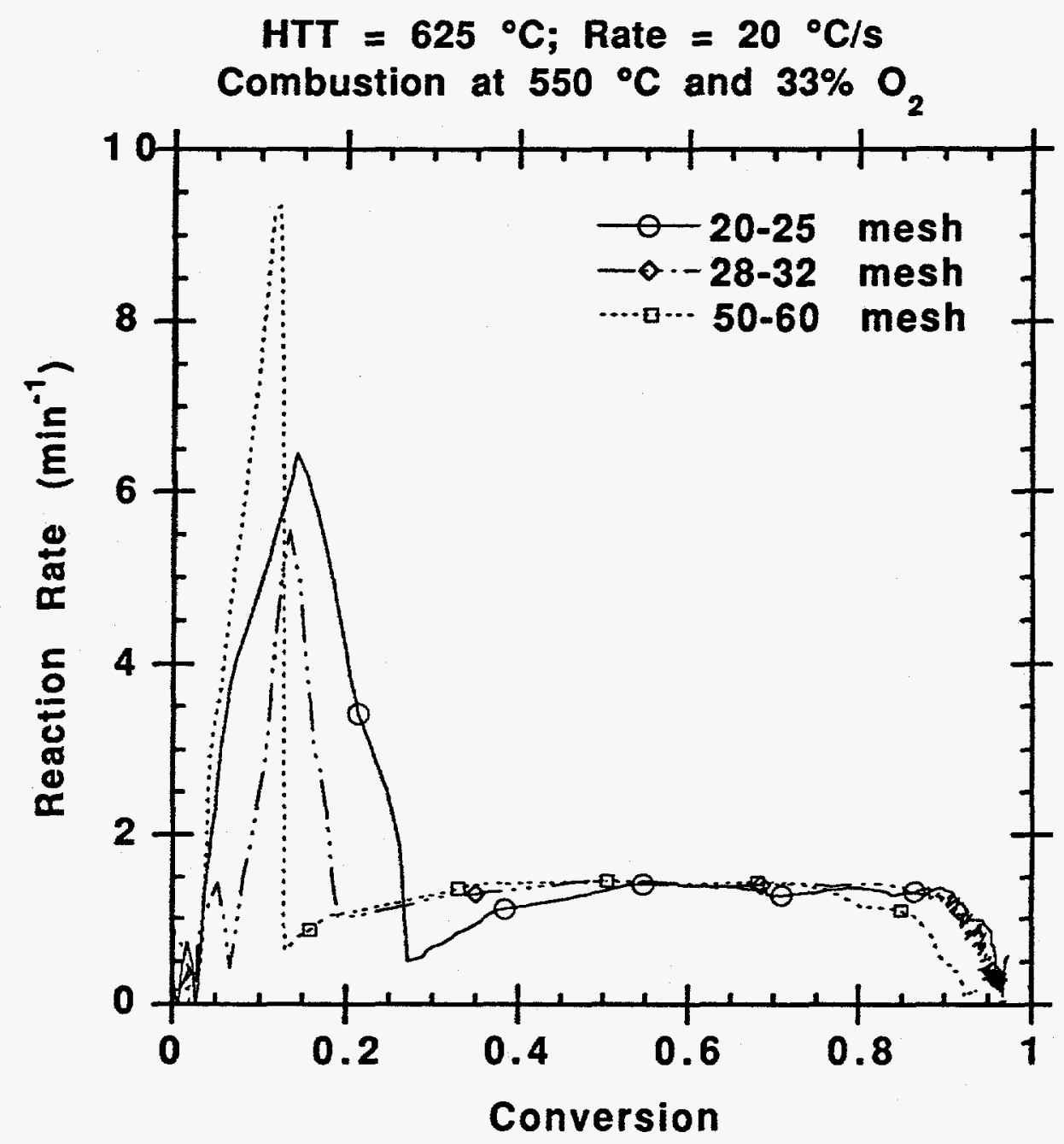

Figure 7: Reactivity patterns for chars of various particle size fractions produced using $20^{\circ} \mathrm{C} / \mathrm{s}$. 


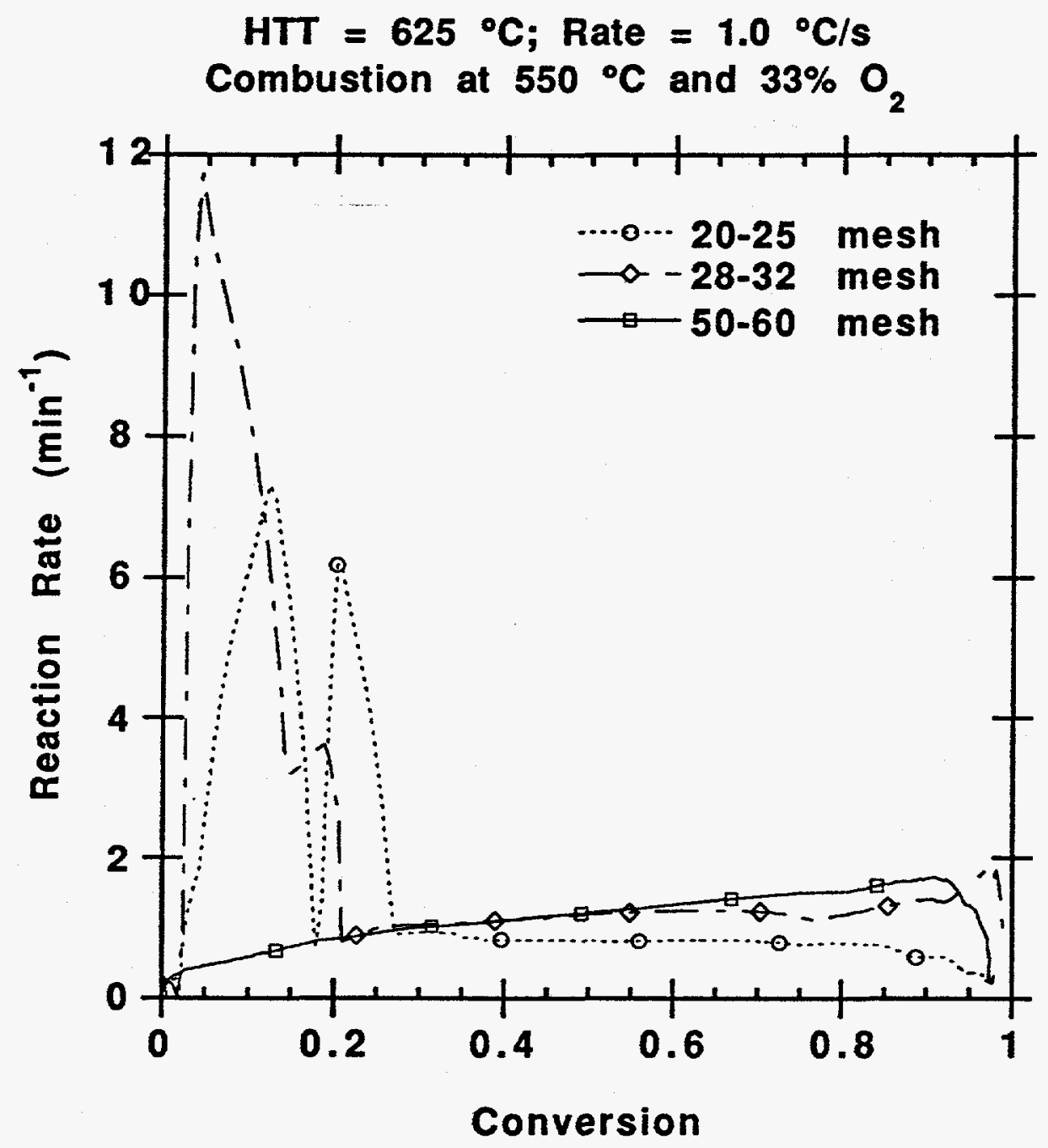

Figure 7: Reactivity patterns for chars of various particle size fractions produced using $1.0^{\circ} \mathrm{C} / \mathrm{s}$. 


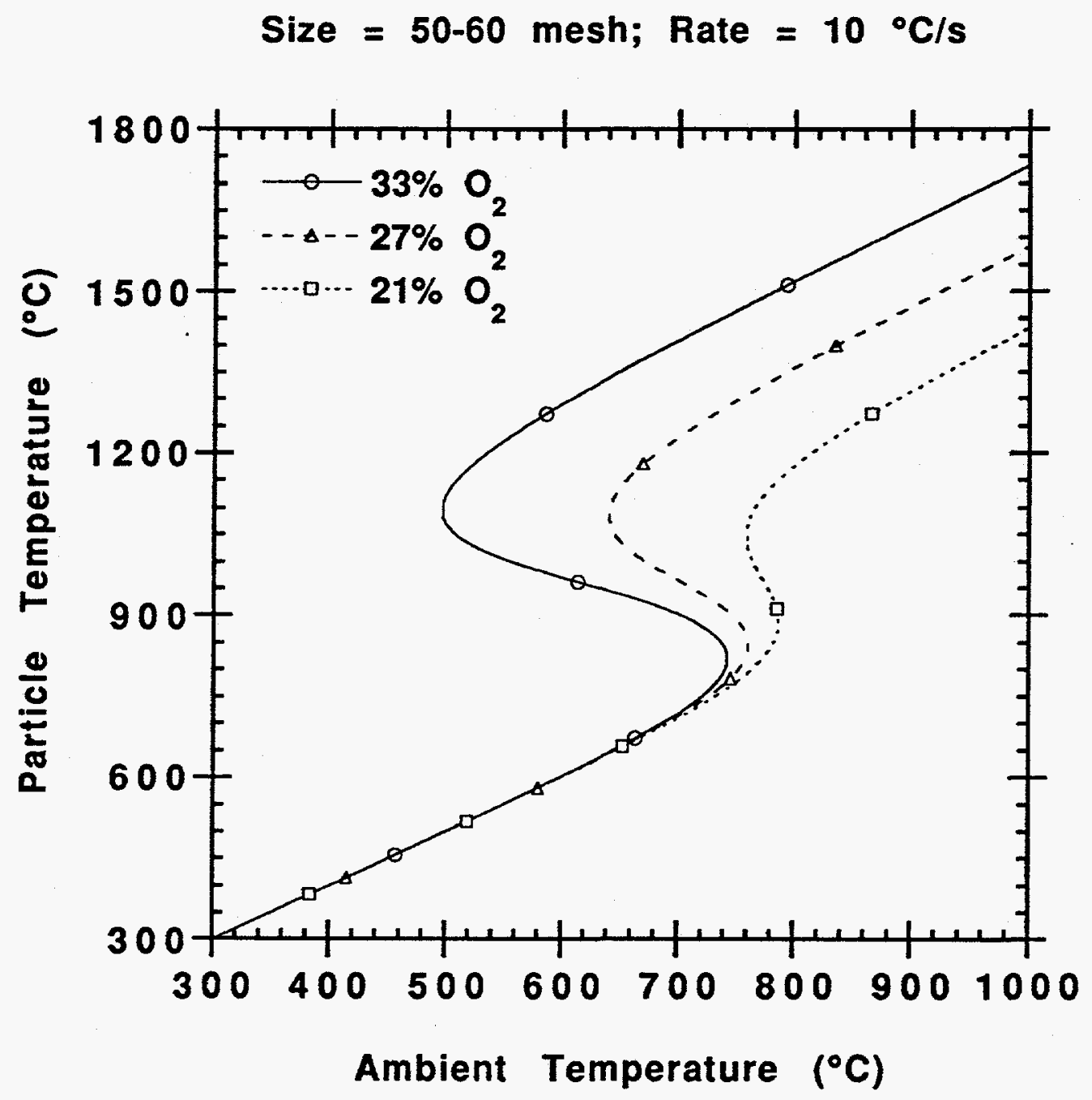

Figure 9: Effect of oxygen concentration for 50-60 mesh fraction chars produced using pyrolysis heating rate $10^{\circ} \mathrm{C} / \mathrm{s}$. 


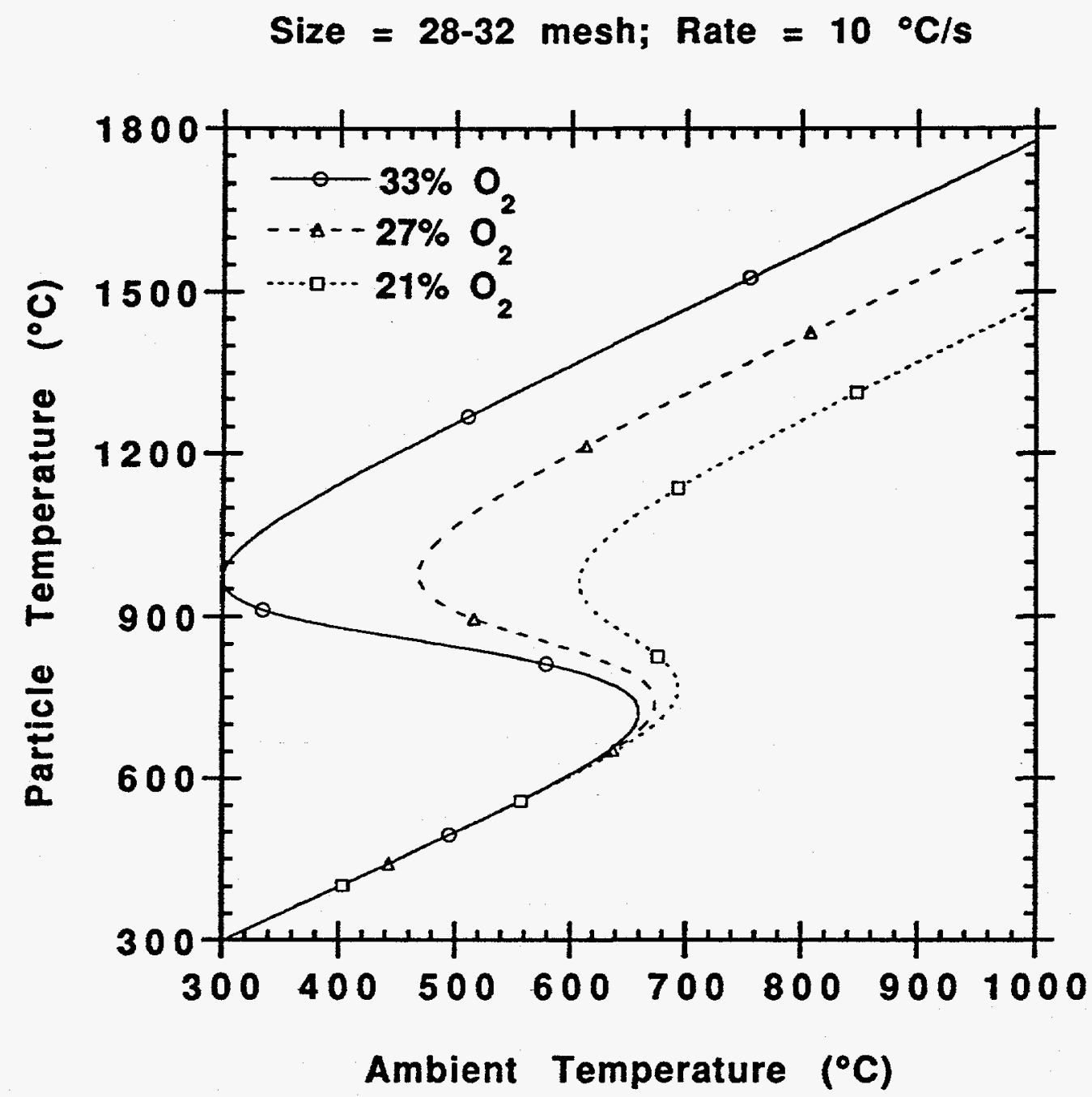

Figure 10: Effect of oxygen concentration on ignition for 28-32 mesh fraction chars produced using pyrolysis heating rate $10^{\circ} \mathrm{C} / \mathrm{s}$. 


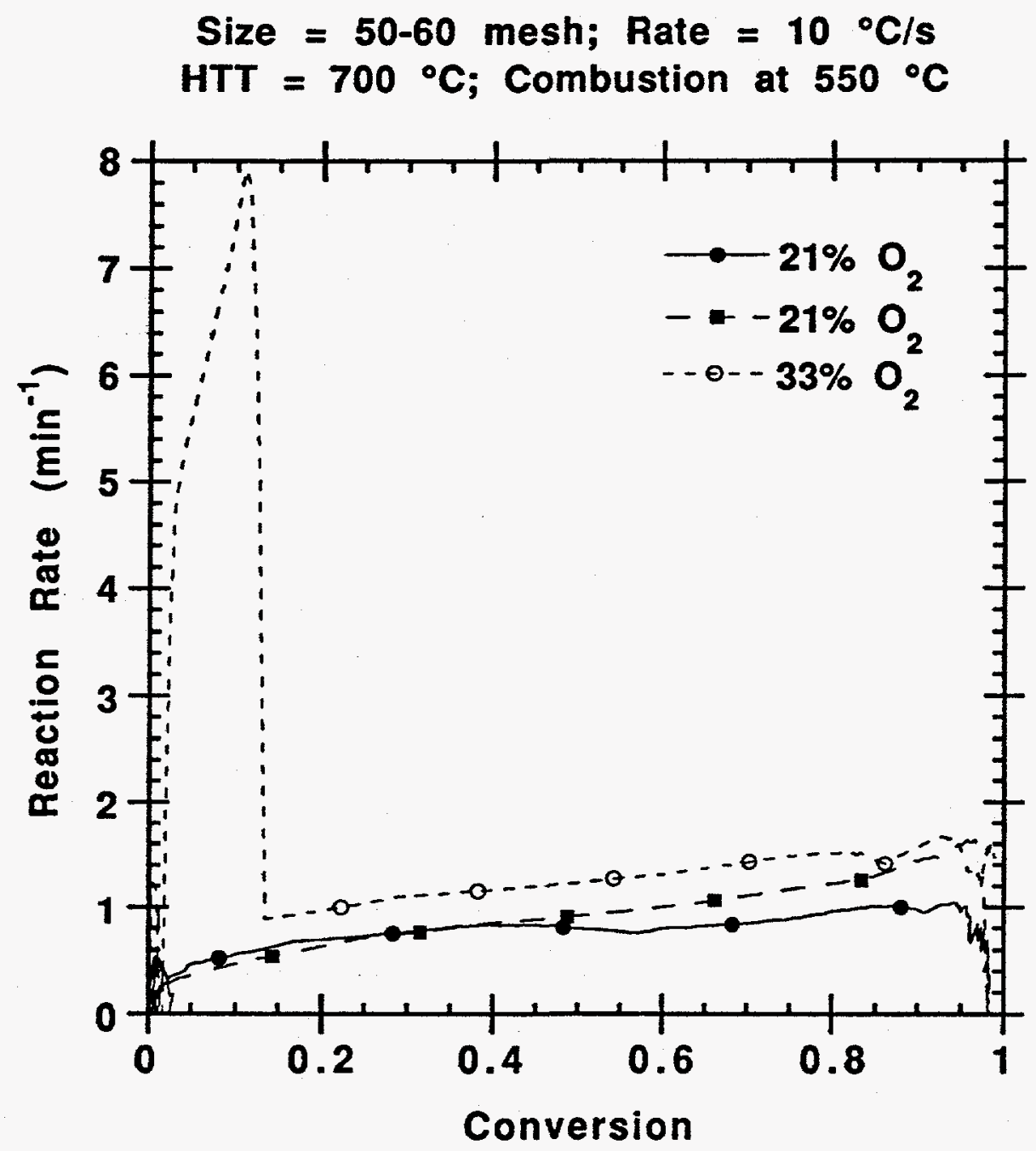

Figure 11: Reactivity patterns for 50-60 mesh fraction chars using different oxygen concentrations. 


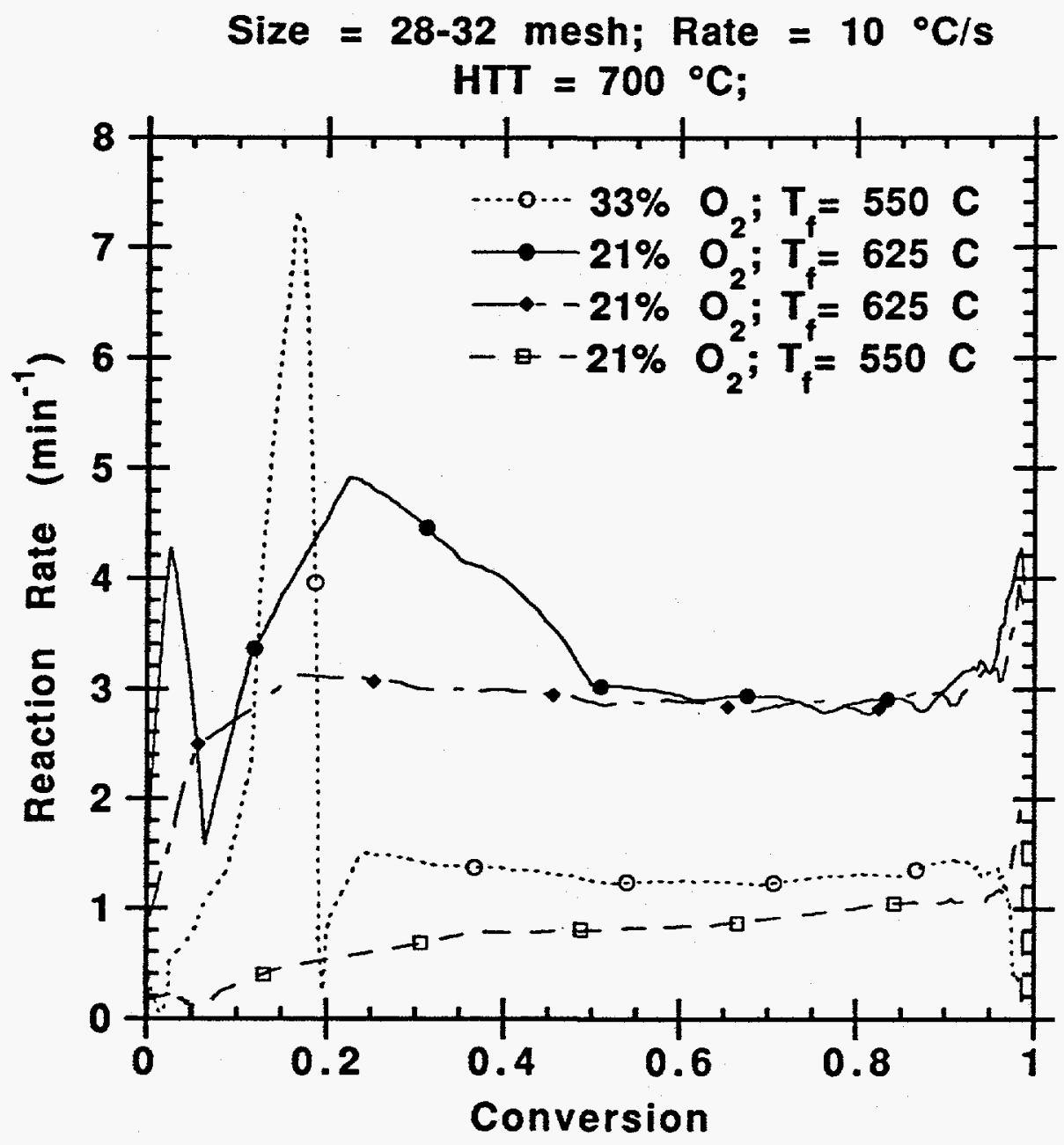

Figure 12: Reactivity patterns for 28-32 mesh fraction chars using different oxygen concentrations and combustion temperatures. 